\title{
RANCANG BANGUN APLIKASI SEGO GUNA MENINGKATKAN JUMLAH PRODUKTIFITAS PENJUALAN PADA WARUNG NASI ONLINE
}

\author{
Muh Rizal Amawi ${ }^{1}$, Taufan kahfi², Sofyan Wahyu Wahidan ${ }^{3}$, Hardi Nurahman ${ }^{4}$, Saiful \\ Asikin $^{5}$, Ummu Radiyah ${ }^{6}$ \\ 1,2,3,4,5,6 Program Studi Teknik Informatika, Sekolah Tinggi Manajemen Informatika dan Komputer Nusa Mandiri \\ Jakarta \\ Jl. Kramat Raya No.18, RT.5/RW.7, Kwitang, Kec. Senen, Jakarta, Indonesia 10450 \\ Co Responden Email: rizal.fdz@ gmail.com
}

Article history

Received Des 11, 2020

Revised Feb 05, 2021

Accepted Feb 20, 2021

Available online Feb 27, 2021

Keywords

Sego Application, Android,

Rice Stall, RUP (Rational

Unifiled Process)

Riwayat

Diterima 11 Des 2020

Revisi 05 Feb 2021

Disetujui 20 Feb 2021

Terbit 27 Feb 2021

Kata Kunci

Aplikasi Sego, Android, Warung

Nasi, RUP (Rational Unifield

Process)

\section{Abstract}

The number of food businesses that use the application by means of purchasing online, making an opportunity for the owner of rice stalls to keep up with the development in business competition, on the basis of it is very necessary an application that can provide the entrepreneurs of rice stalls to participate in the sale of rice stalls online. Therefore, the application of Android Sego is developed through the method of RUP (Rational Unifield Process). In the application Sego the process uses Java programming language with Android Studio. Application can be applied to help rice stalls can accept orders online and provide convenience for buyers to find the rice stalls online. So the goal to increase sales productivity in rice stalls can be realized with this Sego application.).

\begin{abstract}
Abstrak
Banyaknya usaha makanan yang menggunakan aplikasi dengan cara pembelian secara online menjadikan sebuah peluang bagi pemilik warung nasi untuk mengikuti perkembangan dalam persaingan bisnis, atas dasar itu sangatlah dibutuhkan sebuah aplikasi yang di dalamnya dapat mewadahi para pengusaha warung nasi untuk ikut serta melakukan penjualan pada warung nasi secara online. Oleh karena itu dibuatlah sebuah aplikasi android sego yang dikembangkan melalui metode RUP (Rational Unifield Process). Pada perancangan aplikasi sego prosesnya menggunakan bahasa pemrograman Java dengan android studio. Aplikasi bisa diaplikasikan untuk membantu warung nasi bisa menerima pesanan secara online dan memberikan kemudahan bagi pembeli untuk menemukan warung nasi secara online sehingga tujuan untuk meningkatkan produktifitas penjualan pada warung nasi dapat direalisasikan dengan adanya aplikasi sego ini.
\end{abstract}




\section{PENDAHULUAN}

Proses pembangunan ekonomi di Indonesia sudah sangat berkembang dengan berbagai macam usaha dan metodenya, meski sudah banyak usaha-usaha yang sudah besar, usaha kecil pun mempunyai peranan yang sama pentingnya. Banyaknya sumber daya manusia yang dimiliki Indonesia, tidak pula menjamin Indonesia memiliki sumber daya yang memiliki keahlian khusus, dengan tidak sebandingnya lapangan pekerjaan yang ada, dan kurangnya keahlian pada masing-masing pencari kerja, maka peluang untuk membuka usaha kecil menengah masih banyak diminati [1]. Usaha kecil adalah usaha dengan kuantitas tenaga kerja dengan jumlah 5 sampai dengan 19 orang ini merupakan ekonomi produktif yang mandiri, yang dilakukan paling tidak oleh perorangan atau badan usaha yang bukan merupakan anak perusahaan atau bukan cabang perusahaan yang dimiliki, dikuasai, dan menjadi bagian baik secara langsung atau tidak langsung yang berasal dari usaha menengah atau usaha besar [2].

Salah satu bentuk usaha kecil menengah yang diminati adalah warung makan, banyaknya warung makan di Indonesia dalam menjalankan kegiatan usahanya adalah masih menerapkan pemasaran yang bermodalkan spanduk yang ditempatkan pada sisi tempat usaha dan promosi dari orang ke orang secara lisan sehingga untuk mencapai tujuan yang diharapkan, pelaku usaha memerlukan strategi pemasaran yang lebih tepat, yang pada hasilnya akan meningkatkan jumlah volume penjualan untuk meningkatkan laba yang besar [3].

Dunia bisnis membutuhkan adanya sebuah kreasi, dan kreasi itu menentukan tingkat keberhasilan dari suatu pemasaran, dengan memperhatikan produksi barang yang meliputi keinginan pasar kepada konsumen sehingga mampu meningkatkan dan meratakan kemakmuran atau standar hidup [4]. Oleh karena itu pengusaha warung makan dituntut untuk dapat menjalankan usahanya dengan strategi bisnis atau pemasaran yang tepat untuk mempertahankan keberlangsungan usahanya dan tidak mengalami kerugian yang signifikan.

Dari sisi media yang digunakan, sebetulnya banyak cara yang bisa dilakukan, salah satunya E-commerce yang merupakan salah satu dari perkembangan teknologi berbasis internet [5], Dengan E-commerce para Pelaku Usaha Mikro Kecil Menengah (UMKM) bisa memanfaatkan teknologi informasi yang jika diadopsi dan disosialisasikan dengan baik dapat menawarkan beragam keuntungan bagi pelaksana UMKM tersebut, sehingga produk yang diperjualbelikan mampu menjangkau pangsa pasar yang lebih luas hingga ke belahan dunia [6]. Perkembangan sistem pembayaran yang kini sudah secara elektronik menjadikan metode ini banyak menarik minat masyarakat dalam bertransaksi, sehingga penggunaan uang elektronik cocok untuk diterapkan dalam dunia usaha [7]. Atas dasar permasalahan di atas, maka penulis tertarik untuk membuat sebuah aplikasi pada perangkat mobile android bernama SEGO untuk memudahkan para pemilik usaha menengah seperti warung nasi mampu memperlebar dunia usahanya sehingga lebih mudah dijangkau oleh banyak orang.

\section{LANDASAN TEORI}

\section{Konsep Dasar Aplikasi}

Aplikasi adalah sebuah perangkat lunak (software) atau program komputer yang beroperasi pada sistem tertentu yang diciptakan dan dikembangkan untuk melakukan perintah tertentu. Istilah aplikasi sendiri diambil dari bahasa Inggris application yang dapat diartikan sebagai penerapan atau penggunaan. Secara harfiah, aplikasi merupakan suatu penerapan perangkat lunak atau software yang dikembangkan untuk tujuan melakukan tugastugas tertentu [8]. Dalam pengembangannya, aplikasi dapat dikategorikan dalam tiga kelompok, yaitu:

1. Aplikasi desktop, yaitu aplikasi yang hanya dijalankan diperangkat Personal Computer (PC) atau laptop.

2. Aplikasi Web, yaitu aplikasi yang dijalankan menggunakan komputer dan koneksi

3. Aplikasi Mobile, yaitu aplikasi yang dijalankan diperangkat mobile dimana untuk kategori ini penggunanya sudah banyak sekali. 
Sementara pada aplikasi yang akan dibangun adalah sebuah aplikasi mobile yang menggunakan bahasa Java dalam pembangunan dan pengembangannya.

Java adalah bahasa pemrograman yang dapat dijalankan diberbagai komputer, termasuk telepon genggam. Pada umumnya aplikasi yang mengusung bahasa pemrograman Java di kompilasi ke dalam p-code (bytecode) dan dapat dijalankan di berbagai Mesin Virtual Java (JVM) [9].

\section{METODE PENELITIAN}

\section{Metode Algoritma Dikjstra}

Algoritma Dikjstra bisa disebut juga sebagai algoritma greedy. Algoritma ini merupakan salah satu algoritma yang digunakan untuk menyelesaikan jalur terpendek dan tidak memiliki coast yang negative [10]. Algoritma ini akan mencari jalur dengan coast yang paling minimum antara titik yang satu dengan yang lainnya. Selain itu, algoritma Dijkstra juga bisa digunakan untung menghitung total biaya atau cost dari lintasan terpendek yang sudah terbentuk.

\section{Business Model Canvas (BMC)}

BMC (Business Model Canvas) adalah kerangka kerja yang bertujuan mempermudah mempresentasikan business model atau model bisnis [11]. BMC memiliki 9 unsur elemen yang saling berkaitan, yaitu: Customer Segments, Value Propositions, Chanels Channel, Customer Relationships, Revenue Streams, Key Resources, Key Activities, Key Partnerships, dan Cost Structure.

\section{RUP (Rational Unified Process)}

Rational Unified Process (RUP) merupakan proses rekayasa perangkat lunak yang menggunakan pendekatan disiplin untuk menetapkan tugas dan tanggung jawab dalam pengembangan sistem. Dalam RUP juga terdapat fase Iterasi yaitu loop pengembangan yang lengkap sehingga dalam rilisnya (internal atau eksternal) dari executable produk, bagian dari produk akhir yang sedang dikembangkan, menjadi sistem akhir secara bertahap dari iterasi ke iterasi [12].

\section{Android Studio}

Android Studio merupakan sebuah Integrated Development Environment (IDE) khusus untuk membangun aplikasi yang berjalan pada platform android. Android studio ini berbasis pada IntelliJ IDEA, sebuah IDE untuk bahasa pemrograman Java. Bahasa pemrograman utama yang digunakan adalah Java, sedangkan untuk membuat tampilan atau layout, digunakan bahasa XML. Android studio juga terintegrasi dengan Android Software Development Kit (SDK) untuk deploy ke perangkat android [13].

\section{Rancangan Diagram Use Case}

Beberapa Rancangan Use Case Diagram pada Aplikasi Sego yang telah dibuat terlihat pada Gambar 1.

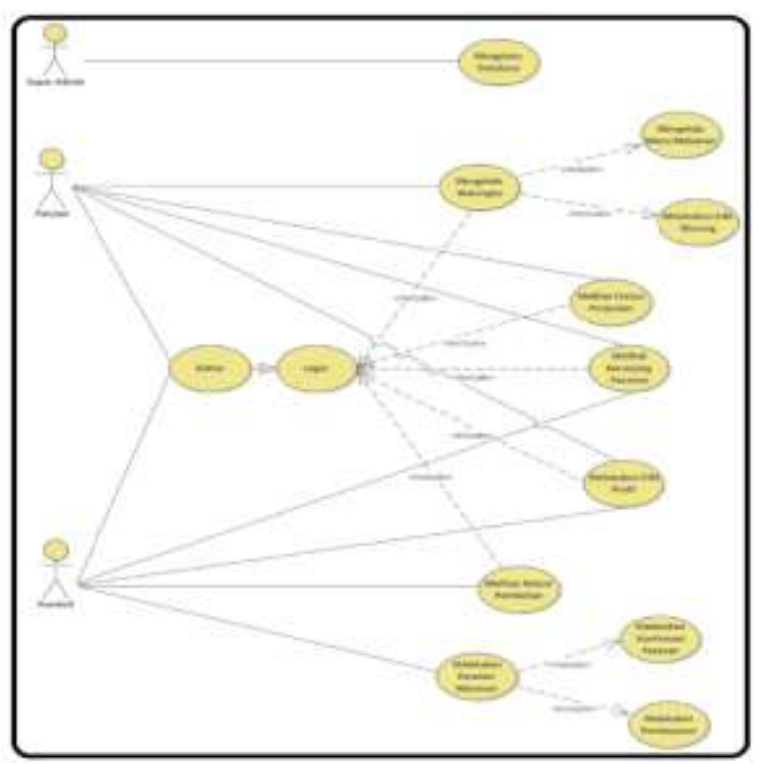

Gambar 1. Use Case Diagram Model SEGO

Rancangan Aktivity Diagram pada aplikasi SEGO ditunjukkan pada Gambar 2, Gambar 3 dan Gambar 4. 


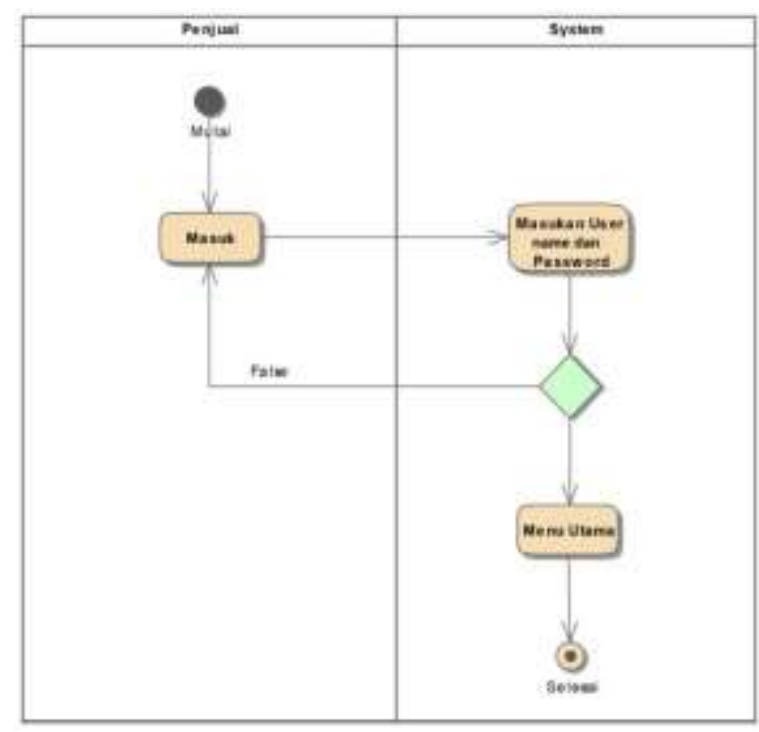

Gambar 2. Diagram Aktivity Login Penjual

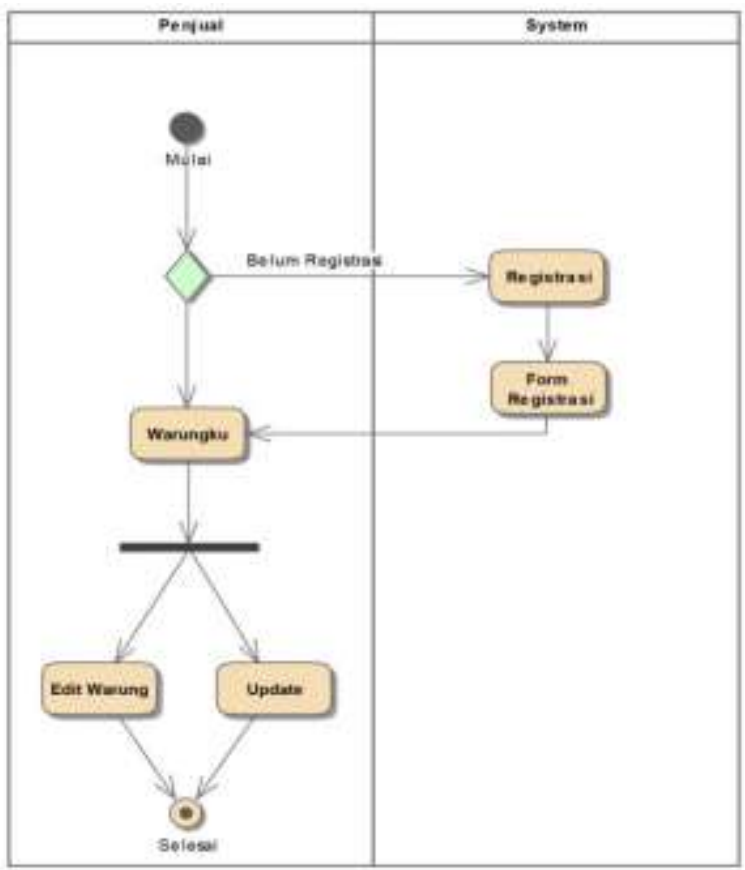

Gambar 3. Diagram Aktivity Warungku

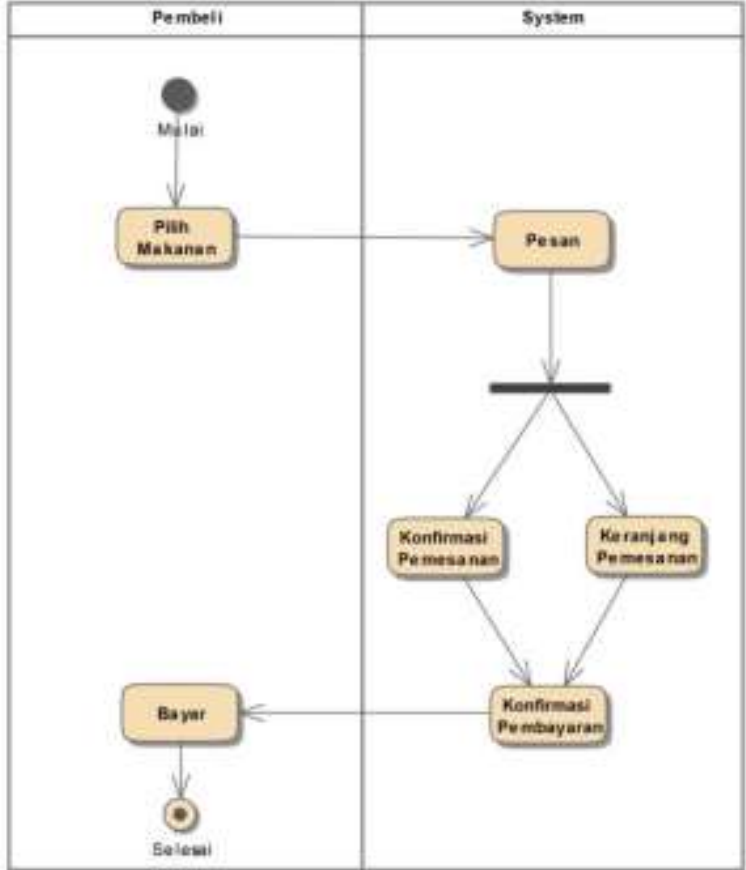

Gambar 4. Diagram Aktivity Pesan Makanan

\section{Rancangan Database}

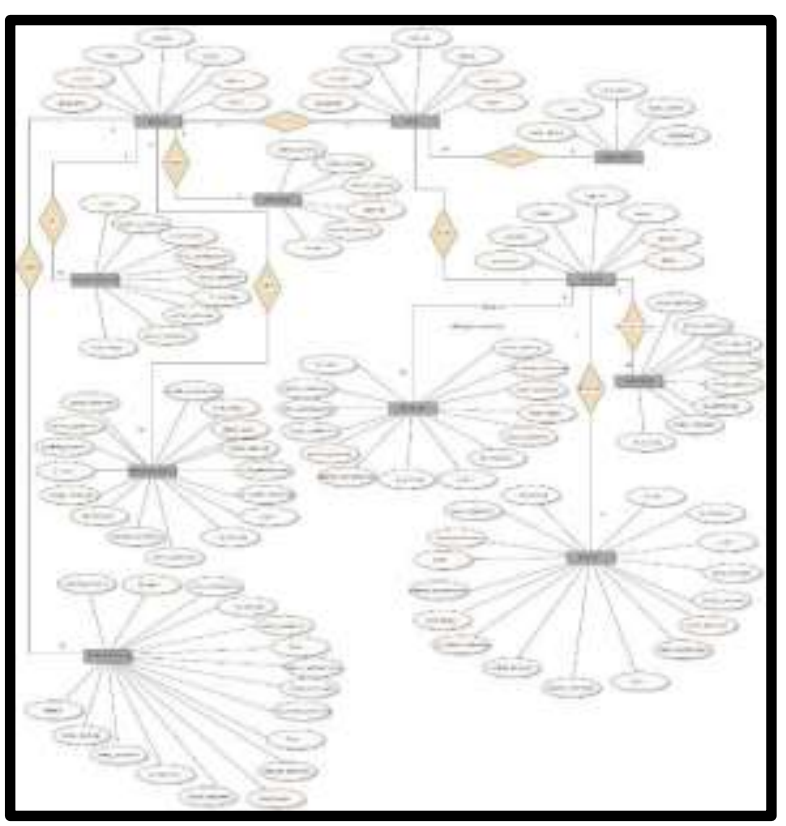

Gambar 5. Rancangan Database Entity Relationship Diagram (ERD) 


\section{HASIL DAN PEMBAHASAN}

Beberapa tampilan Hasil Implementasi aplikasi yang sudah didaftarkan pada Play Store terlihat pada Gambar 6.

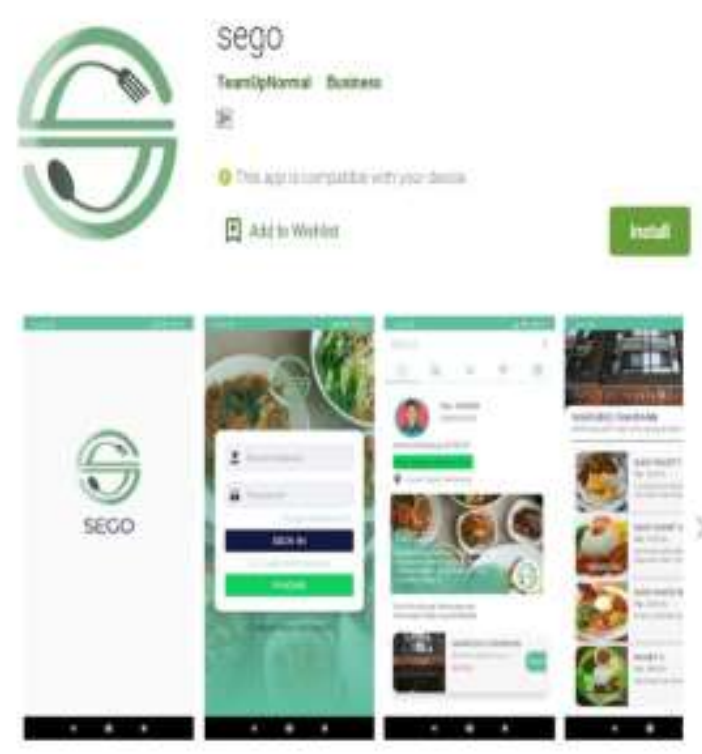

Gambar 6. Hasil Implementasi pada Play Store

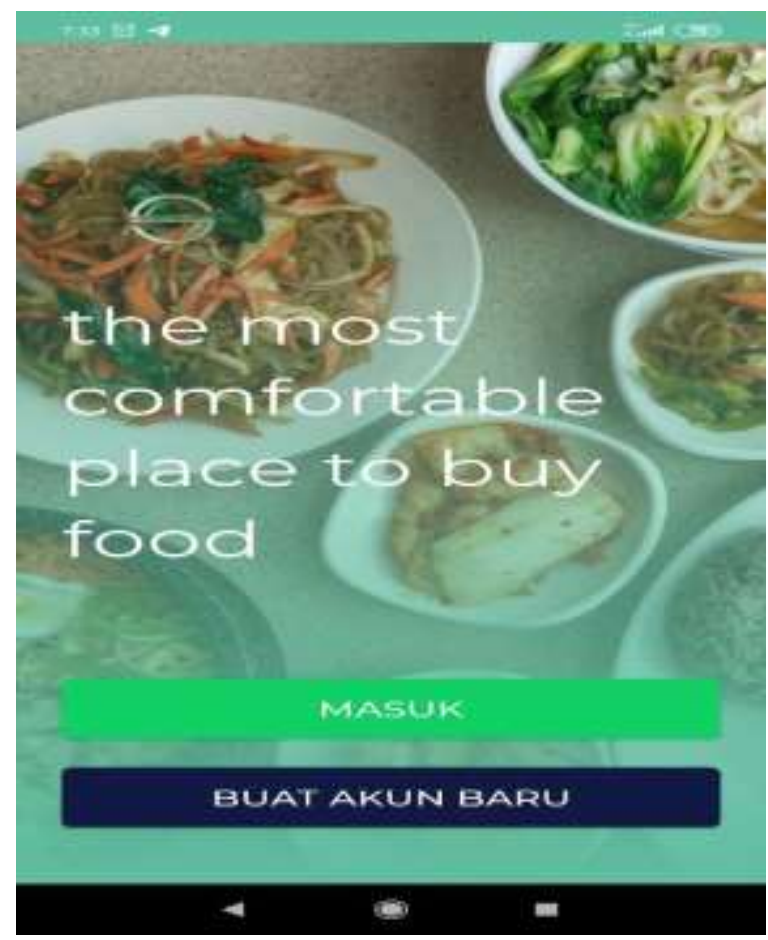

Gambar 7. Tampilan Masuk Aplikasi Sego
Pada Gambar 7 adalah merupakan tampilan ketika masuk Aplikasi Sego bagi user yang belum mendaftar bisa memilih menu buat akun baru dan bagi user yang sudah mendaftar bisa memilih menu masuk.

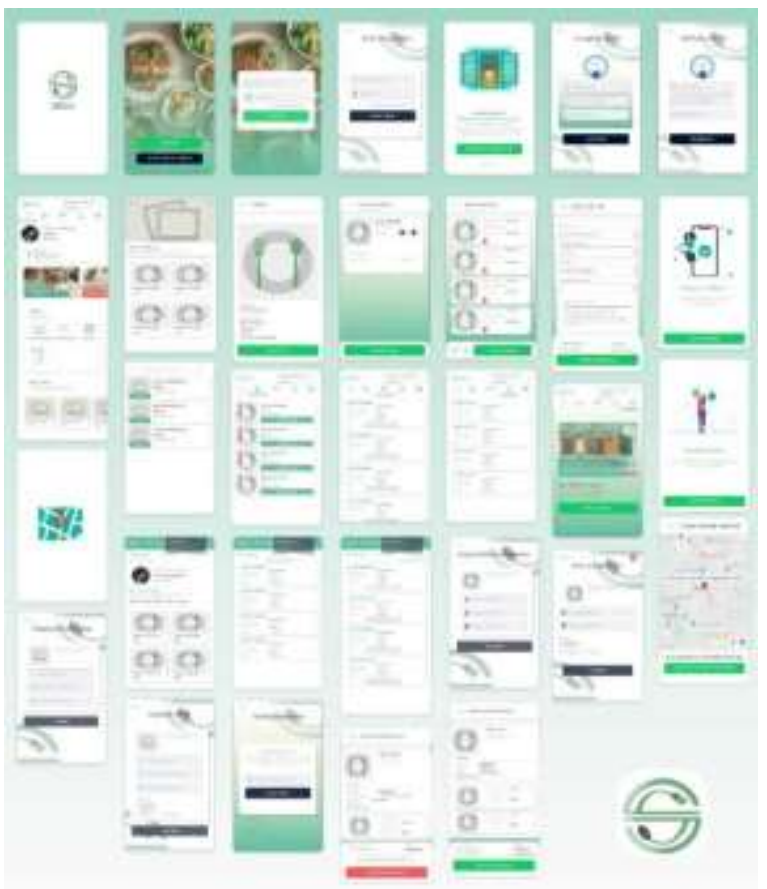

Gambar 8. Rancangan MockUp Aplikasi SEGO

Pada rancangaan MockUp diatas menjelaskan gambaran nyata keseluruhan menu dan fitur-fitur pada aplikasi Sego yang meliputi menu Buka Warung, Pesan makanan, pencarian warung nasi terdekat, menu pembayaran, update makanan, pilih pesanan, dll.

\section{Hardware}

Dalam membangun pembuatan Aplikasi SEGO ini penulis menggunakan Hardware seperti yang terlihat pada Tabel 1.

Tabel 1. Spesifikasi Komputer

\begin{tabular}{|c|c|}
\hline Hardware & Laptop \\
\hline HDD & $500 \mathrm{~GB}$ \\
\hline RAM & $6 \mathrm{~GB}$ \\
\hline Prosesor & $\begin{array}{c}\text { Intel (R) Core (TM) } \\
\text { i3-3120M }\end{array}$ \\
\hline
\end{tabular}




\section{Software}

Kebutuhan Software yang digunakan dalam membangun program aplikasi SEGO yaitu:

1. Sistem Operasi Windows 10 Pro $N$

2. Android Studio

3. Adobe XD

4. Adobe Ilustrator

\section{Pengujian Aplikasi}

Tabel 2 merupakan hasil pengujian dari aplikasi SEGO yang dilakukan dengan menggunakan metode pengujian Black Box.

\begin{tabular}{|c|c|c|c|c|c|}
\hline $\mathrm{No}$ & Senaro & Iest Coss & $\begin{array}{l}\text { Hasitats } \\
\text { dinergikat }\end{array}$ & Hacilerguian & Kesimpulan \\
\hline 1 & Cratuacmet & $\begin{array}{l}\text { Yenarpiline } \\
\text { Inianas ovite } \\
\text { sument }\end{array}$ & 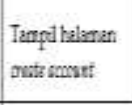 & $\begin{array}{l}\text { Sesciyang } \\
\text { dinsugkan }\end{array}$ & This \\
\hline 2 & Logn & $\begin{array}{l}\text { Merastkhan enni } \\
\text { daspassurad }\end{array}$ & $\begin{array}{l}\text { Tampilaliman } \\
\text { Bine SECO }\end{array}$ & $\begin{array}{l}\text { Sesuritang } \\
\text { tharaglan }\end{array}$ & Thif \\
\hline 3 & 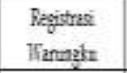 & $\begin{array}{l}\text { Menempilat } \\
\text { byanan registras }\end{array}$ & $\begin{array}{l}\text { Iempt haliman } \\
\text { registrasi }\end{array}$ & $\begin{array}{l}\text { Sestaingang } \\
\text { diturelon }\end{array}$ & 7asi \\
\hline 4 & Eatrinsil & $\begin{array}{l}\text { Menerpilher } \\
\text { byanas esit poot }\end{array}$ & $\begin{array}{l}\text { Iempl balanan } \\
\text { aiff foot }\end{array}$ & $\begin{array}{l}\text { Sesuritan } \\
\text { starapian }\end{array}$ & Thes \\
\hline 5 & $\begin{array}{l}\text { Uflad Ment } \\
\text { Matianen }\end{array}$ & 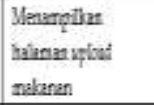 & 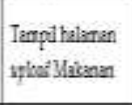 & $\begin{array}{l}\text { Sestainang } \\
\text { dinmzephe }\end{array}$ & hill \\
\hline 6 & Edet îumgke & $\begin{array}{l}\text { Menerpilan } \\
\text { branan edit } \\
\text { ranangh }\end{array}$ & $\begin{array}{l}\text { Iampl halaran } \\
\text { adit varurgins }\end{array}$ & $\begin{array}{l}\text { Sectaingag } \\
\text { diharapkan }\end{array}$ & rist \\
\hline 7 & $\begin{array}{l}\text { Merith } \\
\text { Tenumbs }\end{array}$ & 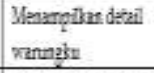 & \begin{tabular}{|l} 
Tampd halanan \\
detal varnogka
\end{tabular} & $\begin{array}{l}\text { Sescai yang } \\
\text { diturathen }\end{array}$ & Thit \\
\hline 8 & $\begin{array}{c}\text { Merith Detal } \\
\text { Matanan } \\
\end{array}$ & $\begin{array}{l}\text { Menzrnilken datai } \\
\text { nalanan }\end{array}$ & $\begin{array}{l}\text { Iampl halenen } \\
\text { detail malaras. }\end{array}$ & $\begin{array}{l}\text { Sesuai yang } \\
\text { dinserphe }\end{array}$ & Thist \\
\hline 9 & $\begin{array}{c}\text { Merilih Pesenan } \\
\text { Makanen }\end{array}$ & $\begin{array}{l}\text { Menemplihe } \\
\text { nakanan yres } \\
\text { digesa. } \\
\end{array}$ & $\begin{array}{l}\text { Iampl halaran } \\
\text { mukannang } \\
\text { tresen } \\
\end{array}$ & $\begin{array}{l}\text { Sestainang } \\
\text { dihmetha }\end{array}$ & Fili \\
\hline 20 & Detal Tranalss & $\begin{array}{l}\text { Melabtuan } \\
\text { yenesinan }\end{array}$ & \begin{tabular}{|l} 
Tampd detal \\
trasselaj fesant
\end{tabular} & $\begin{array}{l}\text { Sestai yang } \\
\text { dinurapka }\end{array}$ & Thit \\
\hline 11 & Stabros Trasalsi & $\begin{array}{l}\text { Melihtikan } \\
\text { Penesanan }\end{array}$ & \begin{tabular}{|l} 
Iempl tates \\
transelisifecann:
\end{tabular} & $\begin{array}{l}\text { Sesuaingeng } \\
\text { dihurgkas. }\end{array}$ & Fint \\
\hline 12 & Fum Perrbetan & Meiarthan dheckout & $\begin{array}{l}\text { Tamplfom } \\
\text { pentelin }\end{array}$ & $\begin{array}{l}\text { Sestainang } \\
\text { diherspkan }\end{array}$ & This \\
\hline 13 & $\begin{array}{l}\text { Dhaistrits } \\
\text { pesenen }\end{array}$ & $\begin{array}{l}\text { logie Warmgin- } \\
\text { Mean Pesan }\end{array}$ & $\begin{array}{l}\text { Tampid detal } \\
\text { pesanan } \\
\text { varungios }\end{array}$ & $\begin{array}{l}\text { Sesuizang } \\
\text { dituphas }\end{array}$ & Thif \\
\hline
\end{tabular}

Tabel 2. Tabel Black Box Testing

\section{PENUTUP}

\section{Kesimpulan}

Dalam penelitian mengenai Rancang Bangun Aplikasi SEGO Guna Meningkatkan Jumlah Produktifitas Penjualan pada Warung Nasi Online berbasis android ini dapat disimpulkan bahwa:

1. Aplikasi SEGO ini bisa menjadi aplikasi yang membantu melakukan penjualan warung nasi secara online

2. Dengan adanya Aplikasi SEGO dapat membantu masyarakat menemukan warung nasi terdekat secara online

3. Melalui aplikasi SEGO masyarakat dapat melakukan pembelian makanan secara online

4. Aplikasi SEGO memiliki user interface yang menarik, sehingga mudah dalam penggunaannya

5. Aplikasi SEGO masih dalam proses pengembangan sehingga hanya bisa diaplikasikan di ponsel pintar berbasis android.

\section{Saran}

Penulis memberikan saran untuk peneliti berikutnya agar bisa meningkatkan dan mengembangkan Aplikasi Sego ini dengan fiturfitur yang lebih banyak lagi dan bisa diterima oleh masyarakat secara luas. Adapun saran-saran yang penulis sampaikan adalah sebagai berikut:

1. Aplikasi SEGO masih membutuhkan proses pengembangan untuk menemukan komposisi yang pas dan tepat dikalangan masyarakat

2. Aplikasi sego masih membutuhkan peningkatan untuk bisa diaplikasikan pada sistem operasi IOS

3. Aplikasi SEGO masih butuh pengembangan dari sisi proses pembayaran dan pengiriman yang belum terintegrasi dengan perbankan atau proses pembayaran digital lainnya. 


\section{DAFTAR PUSTAKA}

R. Franita, "Analisa Pengangguran Di Indonesia," J. Ilmu Pengetah. Sos., vol. 1,pp. 88-93, 2016.

A. Andriyadi and S. Angreani, "Jurnal Sistem Informasi \& Manajemen Basis Data (SIMBADA)," J. Sist. Inf. Manaj. Basis Data, vol. 01, no. 02, pp. 116-127, 2018.

B. Budiman, "Aplikasi Pengolahan Data Persediaan Barang Di Pg Jatitujuh," Infotech J., vol. 4, no. 1, p. 236608, 2018.

[4] F. Andalia and E. B. Setiawan, "Pengembangan Sistem Informasi Pengolahan Data Pencari Kerja Pada Dinas Sosial Dan Tenaga Kerja Kota Padang," Komputa J. Ilm. Komput. Dan Inform., vol. 4, no. 2, pp. 93-97, 2015.

F. E. Nugroho, "PERANCANGAN SISTEM INFORMASI PENJUALAN," J. SIMETRIS, vol. 7, p. 717, 2016. [6] A. S. Suyar, F. E. Bisnis, U. H. Medan, F. E. Bisnis, and U. H. Medan, "Keywords :archive, archiving, MSMEs , Medan Labuhan District .," vol. 33, no. $1,2020$.

H. Kurniawan, "Perancangan Sistem Penjualan Dan Pembelian Sparepat Kendaraan Bermotor Pada Toko Ahmad Service," Semin. Nas. Teknol. Inf. Dan Multimed. 2015, pp. 6-8, 2015.

J. Techno, N. Mandiri, V. Xiii, and N. September, “ISSN 1978-2136 | Rancang Bangun Sistem ... ISSN 1978-2136 |Rancang Bangun Sistem ...," vol. XIII, no 2, pp. 63-71, 2016. [9] M. Natsir, "Pengembangan Prototype Sistem Kriptografi Untuk Enkripsi Dan Dekripsi Data Office Menggunakan Metode Blowfish Dengan Bahasa
Pemrograman Java," J. Format, vol. 6, no. 1, p. 93, 2017.

M. S. Yusuf, H. M. Az-zahra, and D. H. Apriyanti, "Implementasi algoritma Dijkstra Dalam Menemukan Jarak Terdekat Dari Implementasi Algoritma Dijkstra Dalam Menemukan Jarak Terdekat Dari Lokasi Pengguna Ke Tanaman Yang Di Tuju Berbasis Android ( Studi Kasus di Kebun Raya Purwodadi )," J. Pengemb. Teknol. Inf. dan Ilmu Komput., vol. 1, no. August, pp. 1779- 1781, 2017.

D. . Permana, "Analisis Peluang Bisnis Media Cetak Melalui Pendekatan Bisnis Model Canvas Untuk Menentukan Strategi Bisnis Baru," Jur. Tek. Ind. Fak. Tek. Mat. dan IPA, Univ. Indraprasta PGRI, vol. 6, no. 4, pp. 309-319, 2013. [12] M. Taufik, E. Darwiyanto, and S. Yulia, "Analisis dan Implementasi Perancangan Metode Rational Unified Process pada layanan SDB dan Metode Pengujian Product Metric pada Bank Mandiri Cabang Palu Sam Ratulangi (Analysis and Implementation Rational Unified Process Method In SDB Service and Product ," e-Proceeding Eng., vol. 2, no. 3, pp. 7693-7704, 2015. [13] I. Al Fikri, "Aplikasi Navigasi Berbasis Perangkat Bergerak dengan Menggunakan Platform Wikitude untuk Studi Kasus Lingkungan ITS," J. Tek. ITS, vol. 5, no. 1, pp. 4851, 2016. 